\title{
ELENA, DE PETRA COSTA, O SENSORIUM NA CORPORIFICAÇÃO DE UMA ELEGIA
}

\author{
Daiany Ferreira Dantas*
}

\begin{abstract}
Resumo: O presente artigo analisa o filme Elena (2013), da cineasta Petra Costa, tomando os seus aspectos memorialistas a partir do paradigma do corpo vivido, presente nos estudos de Sobchack (1991) e Marks (2000, 2002). A perspectiva fenomenológica destas autoras, que entende o cinema como um campo onde os corpos tanto resultam quanto partilham da memória corporal, compreendem a experiência da espectatorialidade filmica como uma possibilidade articulada pelo sensorium, capacidade cognitiva de interpretação das sensações. Deste modo, também consideram a experiência subjetiva de quem realiza o filme como algo que interfere na percepção da obra. Observamos de que forma a presença do corpo, material e sensorial, nos permite uma análise que considere aspectos de autoria filmica.
\end{abstract}

Palavras-chave: Cinema de mulheres. Sensorium. Corpo vivido.

\section{CINEMA, MEMÓRIA E SENSAÇÕES DO VIVIDO}

"As memórias se vão com o tempo, se dissolvem. Mas, algumas não encontram consolo (...). Você é minha memória inconsolável, feita de sombra e de pedra. E é dela que tudo nasce, e dança" (COSTA; ZISKIND, 2013, p. 32). Com estas palavras, Petra Costa se refere à irmã falecida aos 20 anos, em seu filme Elena (2013), uma elegíaca carta-poema audiovisual, feita de inúmeras imagens do arquivo familiar, entre fotografias, recortes de jornais e vídeos caseiros, além de depoimentos de pessoas que acompanharam a trajetória dos últimos dias de Elena Andrade. Num relato em que a montagem a partir do arquivo, integrando uma obra nova, constitui também um testemunho da percepção da realizadora, que busca restituir o corpo e a arte da irmã.

A paisagem sensorial de Elena é composta de uma matéria afetiva, orgânica e fílmica. Afetiva, pois esboça lacunas e luto, num percurso memorialista ativado pelos arquivos; orgânica, porque a perda de Elena é frequentemente encenada pelos vestígios deixados por ela de sua presença no mundo e seu percurso atribulado rumo a uma identidade artística; e fílmica, porque evidencia o desejo de Petra de integrar esses três mundos na cena cinematográfica, como um relato de perda, resgate e também afirmação de seu próprio lugar como atriz, mulher e realizadora.

Para tanto, levamos em consideração a perspectiva fenomenológica de investigação, que compreende a constituição do campo fílmico a partir do enlace entre o universo sensorial perceptivo dos corpos dos e das espectadoras em sua relação com a dinâmica material dos corpos na tela.

\footnotetext{
* Doutora em Comunicação pela Universidade Federal de Pernambuco. Professora do Departamento de Comunicação Social pela Universidade do Estado do Rio Grande do Norte. Email: daianyd@gmail.com.
} 
Admitimos uma análise fílmica que parte das contribuições de Sobchack (1991) e Marks (2000,2002), considerando o paradigma perceptivo do corpo vivido ${ }^{1}$, inspirado no trabalho de Maurice Merleau-Ponty em torno de uma fenomenologia da percepção que compreende a experiência de pertencimento ao mundo a partir do corpo, como meio e significado.

O corpo vivido sintetiza a dimensão ontológica da experiência vital, sendo, no caso da experiência de espectatorialidade no cinema, capaz de atrelar o visível na tela às sensações corporais que adquirimos no desenvolvimento de nossa percepção cognitiva das condições de nossa realização enquanto seres no mundo, como sujeitos ou nos deslocando em busca da subjetivação. Atua, portanto, no processo de partilha dessa "carne" de memórias presente na matéria fílmica. Trata-se de um sistema diacrítico em que nossa primeiridade deduz dos gestos na tela a sua mobilidade e existência como ser vivido, sendo a visão do espectador a responsável por alinhar e comutar esses processos.

O corpo vivido emerge como uma consciência sensível de si mesmo, de sua potência material e da capacidade de afetar e ser afetado pelo mundo físico. Para Sobchack (1991) esse dialogismo também perpassa as dimensões da experiência cinematográfica como um todo. Ela assinala que a condição de estar diante da tela e endereçar nossa visão às muitas e efusivas formas que desta fluem nos leva também a percorrer o contato com um outro presente naquele espaço, "nós assistimos à experiência expressiva de uma experiência de 'outros', e também expressamos nossa experiência perceptiva" (SOBCHACK, 1991, p. 9) 2 .

Os sentidos de quem presencia a experiência sensível do cinema são parte preponderante na compreensão das formas que dele ressoam. A natureza cinética dos corpos atua nessa intersecção, entre o movimento exterior, dentro da película, e a interioridade física, ou seja, as sensações e tensões ocasionadas pelas fendas dos sentidos - visão, audição, tato. Embora a autora destaque a visão como eixo da potência dos corpos cinematográficos, admite o engajamento de todo o nosso sensorium, nos sentidos que apreendem as coisas do mundo.

Organicamente estabelecidos, os sentidos permitem que gestos do "dentro" do filme estabeleçam uma continuidade com os gestos exercidos "fora" da dimensão fílmica, na constituição de uma dimensão subjetiva e material da tela como continuidade da vida. É pelo olho do espectador que esta experiência se completa, este olhar tanto apreende as condições fílmicas quanto elabora acerca do lugar indireto de ocupado pelo/a realizador/a da obra. A relação do espectador com o cinema passa por uma performance do invisível, na qual a consciência do movimento faz com que este se aproprie do que vê, tomando como referência sua própria performance da existência.

As alternâncias entre visível e invisível como mecanismos perceptivos dessa ontologia do cinema são, portanto, o espaço em que a identificação com os corpos fílmicos se compraz e deles extrai uma incorporação da experiência, por intermédio do referente material e das coordenadas diretivas que estas exercem na tela.

\footnotetext{
1 No original, Sobchack (1991) grafa o conceito com um hífen: lived-body, para dar ênfase à sua constituição diacrítica, aqui apenas utilizamos o itálico.

2 Tradução livre de: "we watch this expressive projection of an "other's" experience, we, too, express our perceptive experience".
} 
No caso deste filme, essa redefinição entre o dentro e o fora da tela se dá também pela percepção da presença corporal da realizadora. A consciência proporcionada pela visão como eixo centralizador está direcionada pela percepção de elementos do vivido não apenas como um experimento morfofisiológico, mas no reconhecimento dos processos vitais instalados pela articulação entre visível e invisível no dialogismo da expressão fílmica.

Percebemos indistintamente a mobilidade de um corpo fora de campo, assim como os preenchimentos que este promove no interior do campo, pelo endereçamento de seu próprio olhar. Há uma partilha que se instala a partir da visão, no reconhecimento desta ótica comutada. Sobchack compreende que:

\begin{abstract}
Realizadores, filmes e espectadores todos usam concretamente a agência do visual e a experiência cinética para expressar experiência — não apenas para e por si, mas também para os outros. Cada envolvido no gesto visível da visão, realizador, filme e espectador, é capaz de comutar essa "linguagem do ser" no que seria o "ser da linguagem", e vice-versa. (SOBCHACK, 1991, p. 21). ${ }^{3}$
\end{abstract}

Tal processo transcende o mero fisiologismo da adequação orgânica aos estímulos sensoriais e torna-se político quando dele se permite o entrelaçamento de questões do visível e do invisível, contorna o mundo fílmico de uma perspectiva de alinhamento do corporal e das tensões sobre estes corpos, que fazem circular as noções de sujeito e objeto.

O corpo vivido é então aquele capaz de projetar e expressar sua situação e perspectiva, reposicionando e endereçando o seu sentido de estar no mundo, sendo tanto um "sujeito de ver e de um objeto para ver" (SOBCHACK, 1991, p. 53) ${ }^{4}$. Sobchack destaca que este entrelaçamento é possível quando reconhecemos o ato de ver como algo que media nossa capacidade de estar no mundo, estruturando o eixo que faz com que passemos de sujeitos do olhar a objetos da visão, pela consciência de que este é um contínuo e cíclico processo de significação. Nesse ínterim está a importância do corpo vivido, que atua como "a 'abertura', através da qual a estrutura invariante da consciência ganha acesso ao mundo, mas é também algo que Merleau-Ponty gosta de descrever como uma 'dobra' no mundo (uma boa insistência de que o corpo é parte da materialidade do mundo)" (SOBCHACK, 1991, p. 64) ${ }^{5}$.

A memória de Petra Costa, que tinha apenas sete anos quando do suicídio da irmã, é recobrada por duas vias no campo fílmico. A primeira delas consta da superfície vívida das imagens factuais que reconstituem a cronologia da existência de Elena, desde pouco antes de seu nascimento, quando sua mãe engravida. Esta, composta pelos vídeos caseiros, clipping de entrevistas e excertos do vasto repertório que consta do arquivo

\footnotetext{
3 Tradução livre de: "Filmmaker, film, and spectator all concretely use the agency of visual, aural, and kinetic experience to express experience - not only to and for themselves, but also to and for others. Each engaged in the visible gesture of viewing, the filmmaker, film, and spectator are all able to commute the 'language of being' into the 'being of language', and back again".

${ }^{4}$ Tradução livre de: "subject of seeing and an object for seeing".

5 Tradução livre de: "the 'opening' through which the invariant structure of consciousness gains access to the world, but it is also what Merleau-Ponty likes to describe as a "fold" in the world (a nice insistence that the body is part of the world's materiality".
} 
privado em audiovisual da jovem que queria ser atriz em Hollywood. A segunda via é o tempo fílmico de Petra Costa no presente, na maior parte das vezes intercalando suas memórias de Elena com tomadas de ruas lotadas, bares e trens, evidenciando a urbanidade e a mescla de rostos e etnias da cidade de Nova Iorque.

Figura 1: Duas Nova lorques.
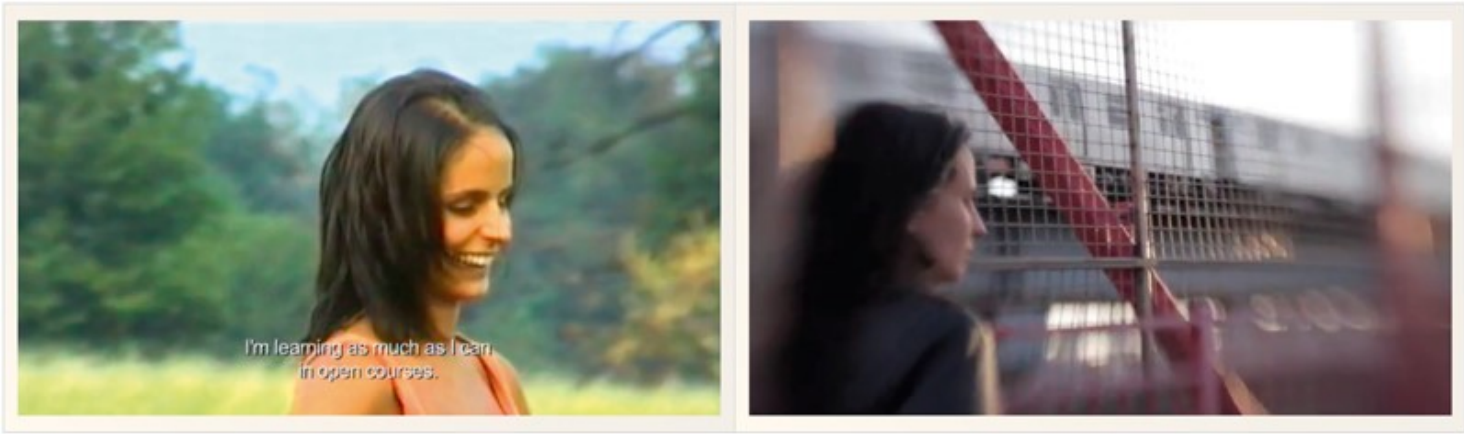

Fonte: Captura e manipulação a partir do original.

Enquanto, nesse primeiro momento, Elena surge alegre e luminosa no flashback de seus primeiros anos naquela cidade estrangeira, a irmã que a busca nos rastros de suas pistas trafega séria e silente por imagens turvas (Figura 1), ativando nuances de melancolia por meio do desfocado ou baixa nitidez. A fotografia de Elena (2013) se encarrega também de demarcar a distância episódica entre esses dois acontecimentos.

A vida de Elena, em princípio se mostrando autônoma e promissora, revisitada pelos olhos amorosos da irmã, coexiste com a busca de Petra pelos motivos que a fizeram sucumbir, seja nas ruas de Nova Iorque, para onde regressa, ou nos vestígios sensoriais dos arquivos, e até mesmo dentro da própria Petra, que declara o peso de viver entre a sombra da semelhança com a irmã e o temor pela herança de seu destino trágico. Ela descreve o sentimento em suas palavras no voice over:

\begin{abstract}
Quatro de setembro de 2003, me matriculei no curso de teatro da Columbia University. Queriam que eu te esquecesse, Elena. Mas eu volto para Nova Iorque na esperança de te encontrar nas ruas. Trago comigo tudo o que você deixou no Brasil. Seus vídeos, diários, fotos e cartas em fitas $\mathrm{k} 7$. Porque você sempre teve vergonha da sua letra e preferia gravar suas impressões (...). Eu ando pela cidade ouvindo a sua voz, me vejo tanto nas suas palavras que começo a me perder em você (COSTA; ZISKIND, 2013, p. 3-4).
\end{abstract}

Assim como neste filme, o curta Olhos de ressaca (2009), primeiro trabalho assinado por Costa, também um projeto de cunho memorialístico e familiar, narra, com o mesmo apreço estilístico da câmera pela nitidez das imagens do passado e o desfocado nos planos que retratam o presente, a longevidade e ternura presentes no casamento de seus avós idosos, entremeando imagens muito claras de planos detalhe de seus rostos, céus e oceanos, quase a ponto de serem estouradas ${ }^{6}$ pelo excesso de luz, resultando num filme bastante solar.

\footnotetext{
${ }^{6}$ Do jargão fotográfico, trata-se de uma imagem com demasiada exposição à luz, o que é perceptível por gradações e texturas que modificam o tom da foto.
} 
Já o longa que o sucede, ainda que matizado por tons suaves em várias das sequências filmadas pela realizadora, poderíamos chamar de filme lunar. A sombra é persistente, tanto nos pouco lapidados vídeos de arquivo quanto nos efeitos das imagens recentes. As tomadas noturnas são constantes. As cenas de palco exaltam a contraluz. Em sequências centrais para a transição temporal, bolas de luzes se dispersam na escuridão, ou surgem como pequenos focos coloridos, um trabalho que destaca o brilho que desponta da sombra. É neste território que Elena "nasce e morre", cinematograficamente falando.

A realizadora consegue a proeza de, num filme em que trabalha com grande parte de um material proveniente de arquivos, que fogem a um maior controle de seu manejo e enquadramento, produzir uma atmosfera sensorial repleta de névoa e de luzes, que intercala paisagens frias e quentes, nas quais Elena desaparece e reaparece. Na memória ficcionalizada, a partir das fotografias e vídeos. E na memória incrustada no corpo de Petra.

A performance material do corpo fílmico de Elena se destaca em cena pela potência de seus movimentos. Na forma como encarna personagens teatrais e em seus passos de dança, eloquentes mesmo nos vídeos domésticos. E pelo enredo construído por Petra para fazer dela - e também de sua mãe, que ocupa a cena preenchendo as lacunas da história - as atrizes de sua trama.

Petra, de inúmeras maneiras, desde o comedimento dos gestos, no presente, às impossibilidades de protagonismo dadas às limitações da tenra idade, no passado - surge, nos vídeos, ainda bebê - assume uma posição secundária no plano do visível. A sua visão do corpo da irmã, interditado na memória, retido nas imagens, nos áudios e nos textos de seus arquivos visitados, é perseguida não apenas para reparar um trauma, mas dele constrói um mundo no qual ambas possam habitar, feito de pedra e de sombra, mas também da luz do campo cinematográfico e da performance do corpo cinético. Nesse espaço-temporal da tela, o corpo de Petra se inscreve sobre o de Elena, não para repetila, mas para que possam se dividir, coexistindo na tela.

\section{TRÊS ATRIZES, TRÊS SENSORIA}

Ao reencenar o corpo de Elena, Petra precisa de dois outros corpos de mulheres: o seu e o da mãe. E de uma outra entidade, que as imanta: a atriz. A realizadora recorda que, segundo o seu pai, ela e a irmã haviam herdado o sonho de "ser atriz de cinema" da mãe. Um sonho que não se concretizou para a primeira, nem para a segunda, cuja vida interrompeu-se tragicamente. 
Figura 2: Elena e Li An, atrizes

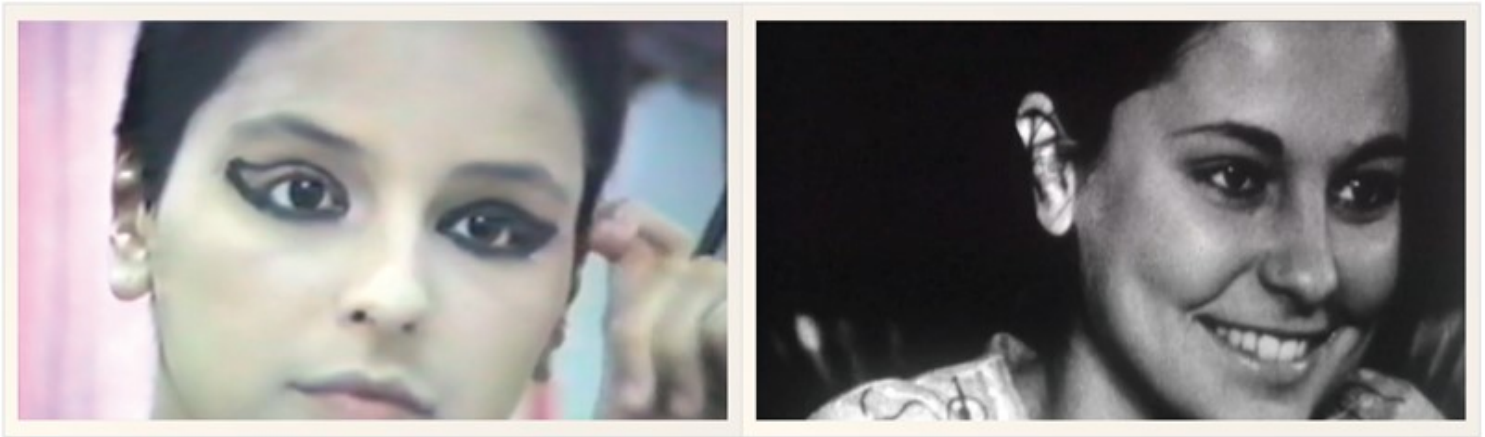

Fonte: Captura e manipulação.

De sonho, tornara-se um ideal mergulhado em sina, desde a morte de Elena. A mãe diz que pouco antes de morrer, a filha dissera que sem a arte não faria sentido algum continuar viva, lamentando-se pela imobilidade física que a tristeza lhe causava. E pede para que Petra escolha qualquer profissão, menos atriz. E qualquer cidade, menos Nova Iorque. Rumos que, como percebemos na sequência inicial do filme, ela não pôde evitar.

Essa memória é reconstruída na abertura e polimento dos objetos de onde emerge a irmã intacta, bela e bailarina. Petra dá à Elena atriz o protagonismo que ela não teve em vida. Mas também burila essa memória, pelos olhos da arte, recriando uma Elena que vive em seu filme. $\mathrm{O}$ que ficará evidente em duas sequências clímax: a restituição do corpo dançarino de Elena e a dança aquática das Ofélias, como veremos mais adiante.

O corpo da atriz, que perpassa as três gerações, se torna um constructo íntegro no mundo fílmico e uma forma de acessar a memória de Elena não pela lembrança da morte, manifestação de uma fisiologia decadente, mas por aquilo que ela tinha de mais intenso e vivo, sua arte. É assim que ela se descorporifica, nos arquivos, e é resgatada dos escombros de seu corpo frágil e vencido. Pela tensão entre arte e matéria, Costa restitui o corpo de Elena.

Percebemos que o trabalho de Costa é construído a partir daquilo que Sobchack (1991) chama de intersubjetividade: em sua visão de realizadora, expressa a experiência do vivido por intermédio do visível, não apenas por si, mas também para os outros e por intermédio dos outros.

E também numa ação de intersensorialidade. Petra ativa a dimensão sensorial e afetiva das imagens, decupando as antigas e construindo as recentes para que habitem um só plano. E se coloca em campo contracenando com os registros de Elena que antecedem e dialogam com aqueles produzidos para o filme. Deste modo, partilha aquilo que vê, compreendendo que "o ato de ver é aquele por intermédio do qual [ela] e o objeto da [sua] visão [se] constituem mutuamente" (MARKS, 2000, p. 183)7 e também são partilhados.

Tal ato de mútuo engendramento, nesse caso, correspondendo ao presente da Petra atriz-diretora-irmã e ao passado de Elena atriz-protagonista-irmã, ao ser lançado no filme, terá, como consequência, o sensorium contido nas visões e emoções da realizadora

\footnotetext{
${ }^{7}$ Tradução livre de: " the act of viewing is one in which both I and the object of my vision constitute each other".
} 
convertido no sensorium do filme, exibindo não a forma como a visão encontrou os objetos, mas as formas nas quais ela os esculpe com o seu olhar, para que esse corpo vivido seja também sentido e partilhado a partir do cinematográfico.

O sensorium fílmico de Costa nos conduz pela trajetória de três atrizes e seus caminhos entrecortados. As imagens de arquivo aproximadas pelo olhar de Petra são norteadas por esse destino. Ela exibe um filme em $16 \mathrm{~mm}$ em preto e branco, no qual a mãe, com apenas 16 anos, é a protagonista (Figura 2). Naquela época, Petra relata por meio do voice over, ela gostaria de ser atriz de cinema, fugir da família tradicional e a previsibilidade de um futuro desestimulante no qual se via casada, caseira e membro da sociedade local. No filme dentro do filme, a mãe, Li An, tem uma expressão melancólica e demora-se executando o desenho de um semblante triste.

Os caminhos como atriz não irão se concretizar. Em vez disso, casa com Manoel, recém-chegado dos Estados Unidos, que regressa ao Brasil inspirado pelos livros de Karl Marx e pelas guerrilhas latino-americanas. Com ele, envereda não pelos filmes, mas pela onda de movimentos sociais, passeatas e prisões políticas que marcam o Brasil no período da ditadura. Numa destas manifestações, a mãe é poupada por estar grávida de seis meses da filha mais velha. A partir daí há um lapso temporal em torno da primeira infância de Elena, vista em poucas fotos filmadas. Segundo Petra, ela nasceu e cresceu clandestina. Vamos encontrá-la crescida, já aos 13 anos, no período de abertura política, nos anos 1980, filmando-se com uma câmera VHS, primeira da família.

E Elena surge como um corpo móvel, usando a câmera como experimento e a casa como palco. Cria cenários afastando móveis e posicionando spots de luz na sala de casa, interage com seu entorno em passos de dança que parecem coreografados. Data deste período também as primeiras cenas entre as irmãs. Petra, ainda bebê, é embalada nos braços de Elena, entre afagos e rodopios. A mãe, que as filma, se queixa da falta de espontaneidade da mais velha, que não permanece "natural" quando a câmera é ligada. Segundo Petra, desde essa época passa a ser treinada pela irmã para ser atriz (Figura 3).

A partir dos 15 anos, com a separação de seus pais, os vídeos caseiros cessam, segundo Petra, a irmã se distancia. Mas, aos 17, as gravações domésticas serão substituídas por imagens públicas da atriz, que ingressa na companhia de teatro $B o i$ Voador, voltada ao desenvolvimento de linguagens experimentais no palco. E surge, como destaque do elenco, em excertos de matérias de revistas culturais, na mídia impressa e televisiva.

Petra utiliza as formas de Elena no palco, dançando de forma repetitiva a coreografia da peça Corpo de Baile (1988), na qual executa movimentos circulares, em voltas que atam uma corda a seu corpo, para explicar a extenuante rotina de seus ensaios, que, segundo seus entrevistados, eram constantes e incansáveis - os outros atores a viam como perfeccionista (Figura 3). 
Figura 3: arquivos de Elena.
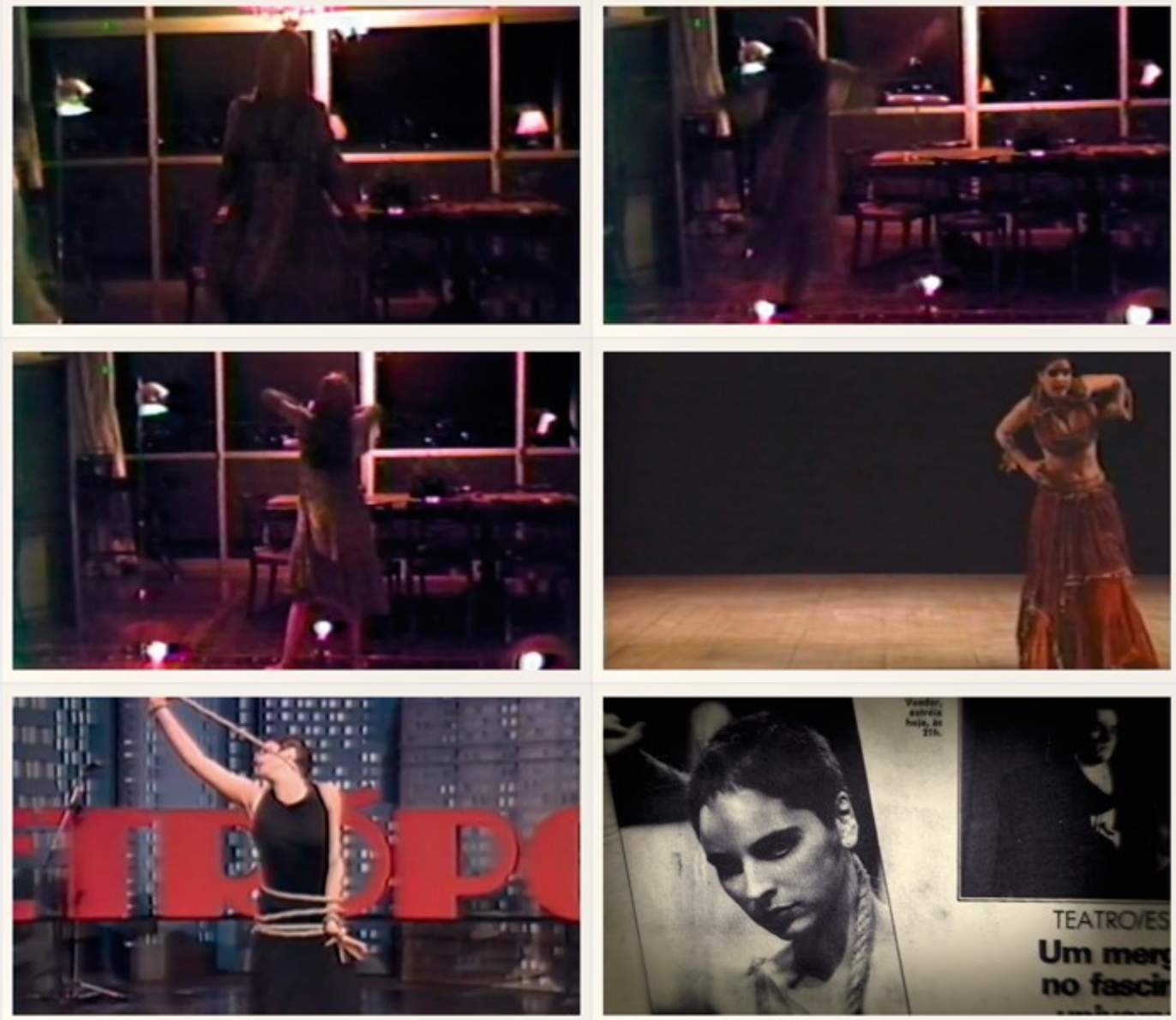

Fonte: Captura e manipulação.

O corpo rodopiante, que busca o giro perfeito, decide que o teatro é pouco, pois o que ela deseja é mesmo ser atriz de cinema - nas palavras de Petra. E as imagens de Elena se tornam a sua voz nos textos extraídos de seus diários e da voz nas fitas cassetes.

Há uma ênfase da câmera de Petra em dar plenitude à Elena por meio desses objetos do passado. Todo o arquivo familiar dispõe à composição de uma cena fílmica que se estende a partir de seus movimentos. E também a uma reverência que a realizadora aplica a tudo aquilo que reverbera memória, como se assim aproximasse e restaurasse a irmã. As imagens e os ambientes são revisitados de modo a se apresentarem como objetos recordação ou objetos fetiche, "utilizados para aproximar uma memória distante, estender uma experiência corporal até a memória (...), como uma prótese da memória" (MARKS, 2000, p. 201) ${ }^{8}$.

O sensorium do filme recria a distância e o exílio de Elena pelo olhar de Petra, que veste a pele da irmã, e encena a dor da saudade Elena, distendida pela potência de sua própria dor e perda. Para mostrar o desalento da irmã, em sua busca pela arte, em Nova Iorque, Petra é vista nas ruas da cidade, cruzando pontes, dentro de um trem, ao som de Elena, no voice over. No processo de cruzar o oceano rumo ao país das fantasias de

\footnotetext{
${ }^{8}$ Tradução livre de: "used to extend bodily experience into memory (...), a prosthesis for memory".
} 
estrelato das três atrizes de sua família, Petra recria a instabilidade das sensações de Elena, retratando sua primavera eufórica, nas novas aulas de canto, dança e atuação, quando conhece "o Coppola"9 num bar, até os relatos de solidão e desamparo, quando as apostas iniciais não se concretizam. A voz de Elena nas fitas vai ficando mais e mais triste. As imagens de suas pequenas conquistas, como o primeiro teste gravado, dão lugar a um contínuo sentimento de fracasso, pela ausência de retorno em suas apostas.

Petra, no presente, adorna a voz e as imagens da irmã com o ornamento do fetiche e da nostalgia, em busca de uma sinestesia que corporifique os deslocamentos do vivido. Nós a vemos caminhando e ouvimos diversas vozes em off que afirmam a semelhança entre as duas. Petra e Elena se confundem em sua condição de estrangeiras em Nova Iorque e no mundo, em sua condição de mulheres e artistas, deslocadas. Desadaptadas, para utilizar a palavra com a qual Petra descreve sua mãe.

No deslocamento solitário de ambas desde o seu país de origem e nos trâmites públicos que as movem numa busca pela transformação do corpo no espaço dos palcos e das telas, a câmera distorcida mostra Petra solitária, enquanto os áudios mergulham a ambas, Petra e Elena, num processo de não pertencimento, perda de referencial e desvalor:

\begin{abstract}
Será que a minha raiz vai conseguir arrebentar asfaltos, canos e prédios para sobreviver e gerar frutos? Sim, se minha raiz fosse forte, grande, mas sinto que minha semente nem chegou a brotar direito ainda. Então, provavelmente numa cidade, ela, se brotasse, miúda e doente viveria. (COSTA; ZISKIND, 2013, p. 17).
\end{abstract}

Marks (2000) explica que as distâncias construídas, pelo uso de imagens distendidas ou na representação de objetos que ela chama de fetiche ou recordação, dentro de um filme partem de um sentimento de exílio. Analisando o cinema diaspórico, afirma que os cineastas remetem ao seu território recriando a sua paisagem ou traduzindo-a por objetos que remetem a essa ausência, enquadrando coisas que traduzem estados ou tecnologias próprias de sua cultura de origem e proporcionando uma sensação sinestésica nos espectadores, tanto pela identificação, quanto pelo estranhamento daquele sensorium.

Marks entende que o cinema de deslocamento cultural geralmente tem seu foco na perda, tentando constituir um passado e uma memória do que ficou para trás: a língua, os traços dos costumes, as referências do lugar, pois "testemunha a reorganização dos sentidos que se reposicionam, e os novos tipos de conhecimentos sensoriais que se tornam possíveis quando as pessoas se deslocam entre as culturas" (MARKS, 2000, p. 195) ${ }^{10}$.

Guiada por seus vídeos e sua voz gravada, resíduos remanescentes do passado de Elena, os deslocamentos de Costa vão além de um referente de país ou tradição. Sua busca é pela restituição do seu lugar no mundo, como atriz e como mulher, um lugar que foi erodido pela perda da irmã.

Para isto, ela precisa, antes, restituir o corpo frágil de Elena, dar-lhe uma concretude e um propósito, devassando o sensorium de seus indícios e a partir deles erigindo o

\footnotetext{
${ }^{9}$ Refere-se a Francis Ford Coppola, diretor de cinema estadunidense renomado.

10 Tradução livre de: "witness to the reorganization of the senses that takes place, and the new kinds of sense knowledges that become possible, when people move between cultures".
} 
sensorium feito do conhecimento do corpo vivido. E é este vivido, feito de experiência resgatada entre seus desejos fabulosos e sua fragilidade orgânica, que emerge das sensações e gestos da irmã, explorados até o esgotamento das possibilidades do arquivo. A integralidade da memória de Elena é evocada no despertar de seus sentidos e na inteireza de seu corpo fílmico, na reconstituição que Petra alça, numa dimensão sensível capaz de projetar a sua materialidade de atriz, irmã e jovem mulher.

As imagens do filme surgem mais complexas na medida em que se aproxima a sequência que relata a morte de Elena. Sua imagem, antes feliz e sorridente, torna-se uma memória triste nas lembranças evocadas, época de constante choro e reclusão. Petra lembra, desta época, dos sinais de tristeza que a sua percepção imatura encontrava na irmã. O dia em que ela lhe contou a história original da Pequena Sereia, " em que ela sofre pra se tornar mulher, perde a voz e morre" (COSTA; ZISKIND, 2013, p, 21) e a imagem dos olhos tristes do cachorrinho de pelúcia que ela havia lhe induzido a mostrar no jogo escolar de show and tell ${ }^{11}$.

A voz em off das paisagens de Elena se vão, dando lugar ao voice over de Petra, que incorpora o tom da irmã, recitando trechos dos últimos e doídos escritos deixados por ela, sua carta de despedida. O último dia de Elena é reconstituído com obsessiva riqueza de detalhes. Sua mãe surge e ocupa os cenários, elas buscam, nas ruas do bairro, o edifício onde moravam. Costa entrevista a última pessoa a falar com Elena ainda viva, um amigo que desconfiou do estado choroso e da quebra de um compromisso ao telefone. Petra, que não estava quando sua mãe encontrou a irmã desmaiada, e Li An percorrem os cômodos da casa, sombria com seu revestimento de madeira escura. Li An relembra a noite anterior: o pedido de que Elena tentasse não demonstrar tanta tristeza diante da irmã menor, o choro convulsivo dela antes de adormecer, o pôster que ela havia pendurado na parede do quarto - um cartaz da peça Elektra - exibindo um rosto lacrimoso, no qual Li An reconhece feições trágicas semelhantes às de seus desenhos.

Elas refazem os passos até o encontro com o corpo inerte, o sangue nas paredes, a carta presa à bobina da máquina de escrever, a dificuldade de encontrar quem auxiliasse no socorro. Vão até o hospital e revivem os instantes de inquisição quanto às condições de Elena, ainda viva e demandando cuidados, até o desfecho da exibição do laudo, exposto no quadro fílmico como se fora uma radiografia. Dele, a câmera extrai a crueza do estado débil do corpo de Elena. Uma imagem borrada aos poucos se afirma num plano fechado. Nela está escrito: O coração pesava 300 gramas (Figura 4). A câmera percorre as letras, exasperada, até a conclusão do perito, exposta numa tomada duradoura: Suicídio.

Um silencioso fade out é executado. E dele emerge a imagem de Elena, no palco, segurando um spot de luz. Em seguida, movimentando-se vertiginosamente no escuro, ao som de Valsa para a Lua, de Vitor Araújo. Petra realiza toda uma fisiologia da dor, ao restituir o corpo ferido e dissipado da irmã. $O$ coração se partira, frágil e mínimo, na nitidez do texto no laudo. Entretanto, dessa imagem sobressai o corpo da Elena atriz, mágico e desdobrável no palco onde "dança com a lua".

\footnotetext{
${ }^{11}$ Em tradução livre: "mostre e conte uma história".
} 
A atriz, a jovem, a irmã, a filha, o coração miúdo, regrado, a imagem que desaparece, passam a viver no mundo fílmico como um corpo restituído. Descorporificada pelas condições do espaço fílmico. Ganha uma autonomia e uma continuidade no plano das sensações.

Figura 4: 0 coração de Elena.

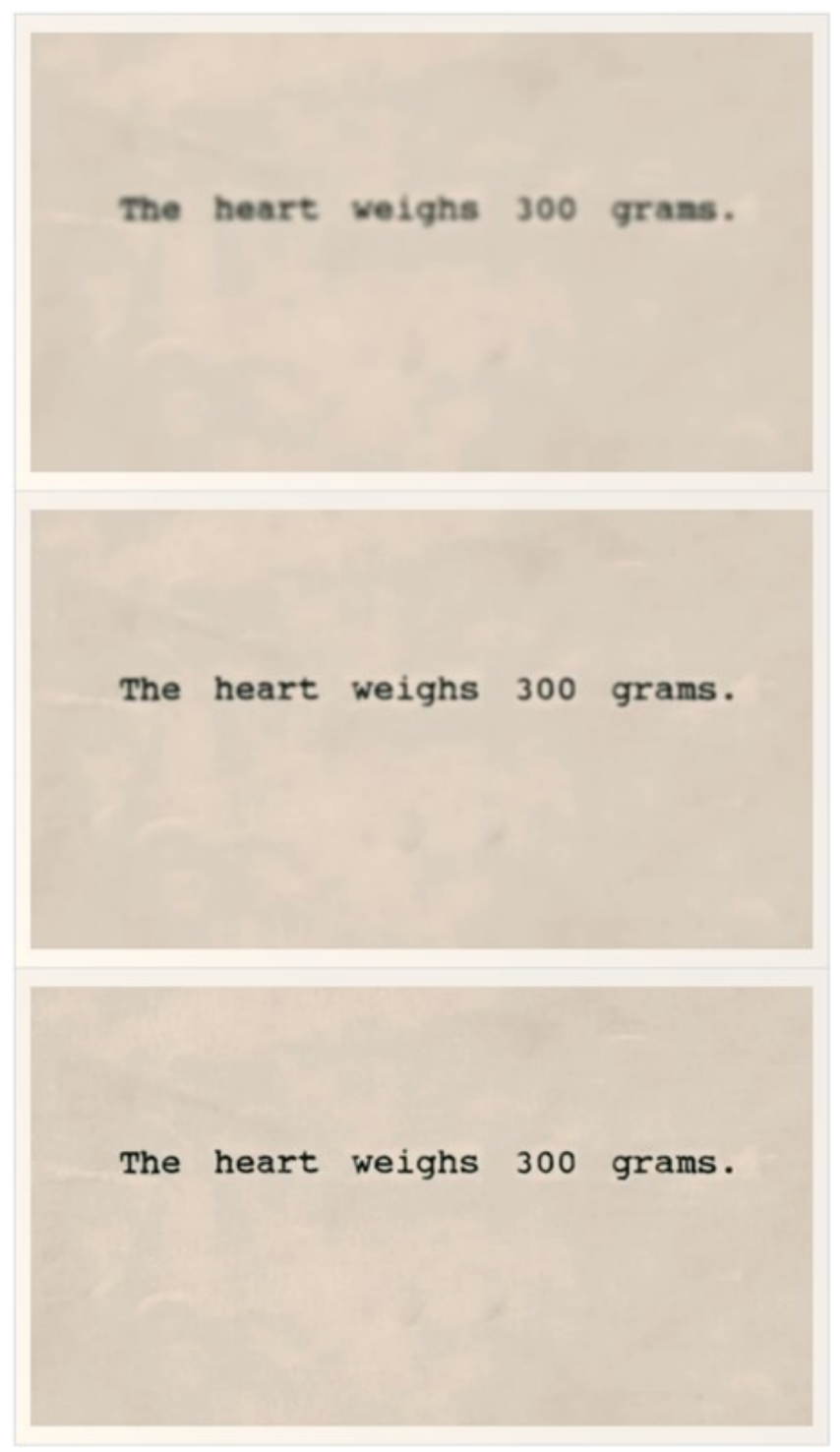

Fonte: Captura e manipulação.

Quando menciona o olhar háptico, aquele que escrutina as imagens a pretexto de tocá-las, como se os olhos fossem um órgão tátil, Marks (2002) diz que a visão háptica frequentemente se mostra pela forma como exibe imagens que guardam memórias afetuosas de pessoas ou coisas, captadas em estado de quase desaparecimento, retendo seus rastros por intermédio da fugacidade luminosa da película.

A cena do laudo, a letra crua com as descrições orgânicas de Elena, sucedida pela imagem da atriz no palco, desfazendo-se nas sombras até tornar-se uma luminosidade móvel e cíclica, substitui o desaparecimento de seu corpo físico por um corpo 
desterritorializado (Figura 5), um rastro de luz que desponta da memória reconstituída por Petra - auxiliada por sua mãe - para tornar-se uma ficção da memória da matéria fílmica. Uma imagem que permanece, sustentada pelo afeto.

Figura 5: Dançando com a lua.
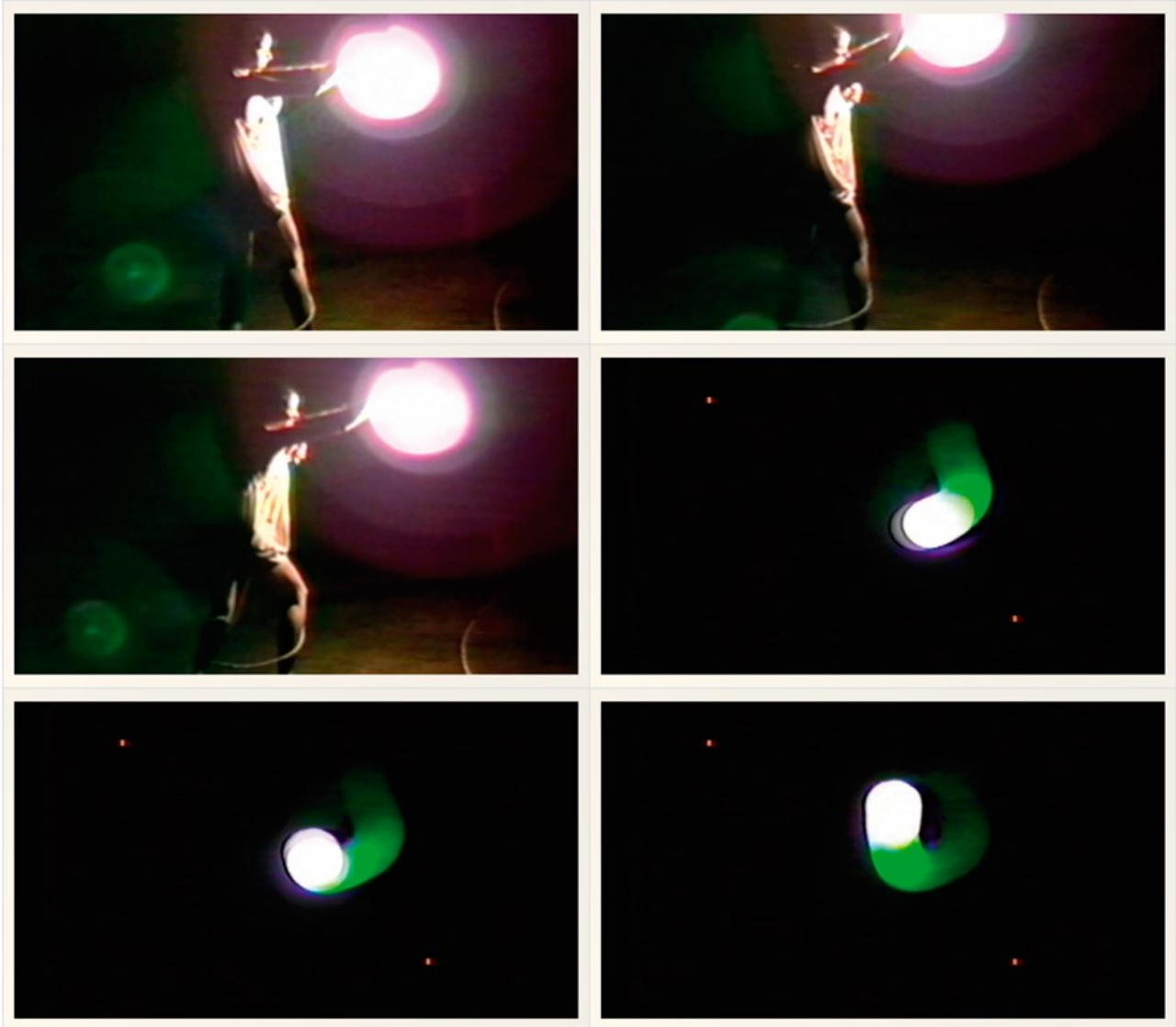

Fonte: Captura e manipulação.

Marks (2002) compreende que algumas imagens repletas de indícios de desaparecimento - como os rastros de luzes no palco, deixados pela dança realizada por Elena, com seu corpo submerso na escuridão cênica do palco - são registros melancólicos que buscam deter o desaparecimento de uma imagem, à maneira de um luto. A imagem da irmã amada destitui-se da tenacidade corpórea para tornar-se um vestígio da perda. E, assim, não apenas acalentá-la, a respeito de sua partida, mas permanecer viva na dimensão do filme. Para a autora:

\begin{abstract}
Enlutar-se pela morte de uma imagem é muito menos traumático, claro, do que o luto por uma pessoa amada. No entanto, defendo que o envolvimento com uma imagem que desaparece possui alguns resultados para a formação da subjetividade, ou, precisamente, uma subjetividade que reconhece a sua própria dispersão. Estas obras de imagens que desaparecem incentivam o espectador a construir uma ligação emocional com o próprio meio (MARKS, 2002, p. 109). ${ }^{12}$
\end{abstract}

12 Tradução livre de: "Mourning the death of an image is far less traumatic, of course, than mourning a loved one. Yet I argue that engaging with a disappearing image has some results for the formation of 
A carga emocional da morte prematura e trágica de Elena é abrandada pela contemplação de seu desaparecimento na dança com a lua (Figura 5). Como um corpoluz, que se torna, portanto, perceptível em sua forte carga performativa e sensorial, resignificando a finitude de sua matéria no espaço-temporal cinematográfico, onde a sua imagem é intensa e vívida por sua capacidade de gerar afeto. Entretanto, ela desaparece após ser recuperada, numa memória fílmica que dança.

\section{PRESENÇA E DESAPARECIMENTOS COMO ELEMENTOS DO SENSORIUM FÍLMICO}

Após o desaparecimento de Elena, finda a exploração arqueológica e afetiva das imagens e vozes deixadas pela irmã. É no corpo de Petra e de Li An que agora Elena irá viver, como luto, saudade e no reconhecimento de uma memória física da dor, partilhada pelas três. Para falar do sentimento de tristeza de Elena, a mãe leva a mão ao peito, gesto que Petra também repete.

As imagens agora estão centradas na infância de Petra, vídeos mostram seu rosto contrariado, sendo deixada na escola. Planos exibem cópias de seus laudos, registrando diagnósticos de depressão e ansiedade. Exibem também a solidão da mãe. Vista numa gravação dos anos noventa caminhando sozinha e mais magra, em meio a árvores. As imagens da infância são substituídas por um plano geral de Petra correndo, já adulta e de costas, rumo a uma imensidão de grama. Petra continua a sua longa carta para a irmã, conta que aos 21 anos se deu conta de que havia ultrapassado a sua idade em vida, como se estivesse comemorando a sobrevivência a um rito de passagem.

Menciona os períodos de incerteza no momento de definir da escolha da profissão. Sua ansiedade ao escolher teatro e se deparar com a sombra da tragédia de Elena. A dor de Petra se mistura ao sentimento de Li An: "se ela me convence que a vida não vale a pena, eu tenho que morrer junto com ela?" (COSTA; ZISKIND, 2013, p. 40) - dizem ambas, de forma sobreposta.

E a sobrevivência de ambas, no filme, surge das mesmas formas de vida que restituíram o corpo de Elena, da construção de uma paisagem sensorial na qual o corpo vivido se dilate, como uma experiência da existência que atravessa as condições de ser mãe, filha, mulher e atriz e toma formas fluidas por onde possam escapar do cárcere do luto e do destino.

Sobchack esclarece que o corpo vivido cinematográfico passa de privado e invisível, como parte de uma experiência individual a uma ordem da "corporificação para o visível, público e [da] sociabilidade intersubjetiva de uma linguagem direta da experiência corporificada" (SOBCHACK, 1991, p. 11) ${ }^{13}$.

Numa das sequências mais sinestésicas do filme, essa corporificação do invisível num mundo das sensações acessado pela via da arte se faz presente. Petra é vista já adulta e atriz, tendo encenado Hamlet diversas vezes. Com sua mãe e outras jovens (Figura 6),

subjectivity, or, precisely, a subjectivity that acknowledges its own dispersion. These works of disappearing images encourage the viewer to build an emotional connection with the medium itself".

${ }^{13}$ Tradução livre de: "embodied into the visible, public, and intersubjective sociality of a language of direct embodied experience". 
todas trajando vestidos floridos de tecidos leves, mergulham e se deixam arrastar nas águas claras de um rio. Vistas em tomadas aéreas, experimentam a temperatura diurna e o fluxo da sutil correnteza que as transporta. Petra diz: "Me afogo em você, em Ofélias", ao som da música de Maggie Clifford, I turn to water, cuja letra menciona: "I'm sick with love, touch me. I turn to water".

Figura 6: Balé de Ofélias.
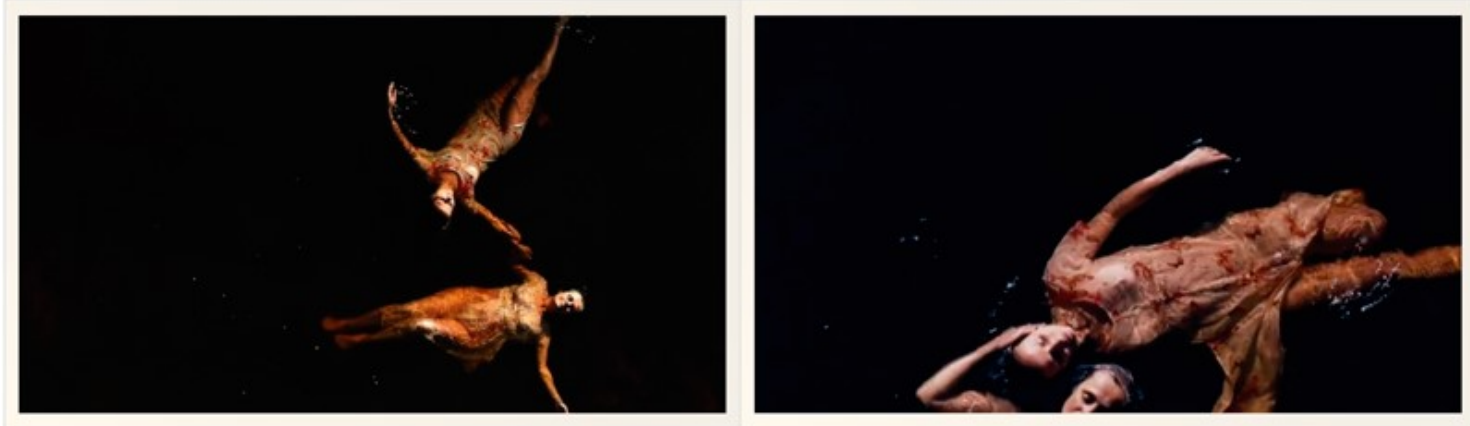

Fonte: Captura e manipulação.

A experiência aquática de celebrar Ofélia, personagem shakespeariana que encena o suicídio como último recurso de expressão das dores de sua existência, é resignificada nesta sequência, um batismo purgador, no qual os corpos vividos de mãe e filha flutuam numa experiência multissensorial na água reparadora, útero e fonte, que conduz a um renascimento.

Renascimento do corpo de Elena, recriado para o mundo da arte. Do corpo criador e objeto fílmico de Petra, em seu experimento de conhecer a irmã para, assim, sobreviver. Renascimento na performance da atriz e realizadora, construindo campos e formas de habitar o visível. Renascimento do corpo maternal de Li An, onde se dissipam as culpas.

Nas últimas imagens do filme, Petra dança, sozinha, nas ruas de Nova Iorque. A sua voz evocando a memória da irmã, que faz com que tudo nasça e dance em sua vida, é sucedida por imagens dançarinas de Elena. Não mais um corpo que moveria a pele de Petra, como uma herança, em seus anseios de uma sina artística, mas, uma cena corpórea autônoma.

Elena (2013) mostra-se uma obra ímpar para a observação fenomenológica do corpo vivido em sua tríade matéria-memória-percepção, permitindo uma análise que evidencie a relação entre a realização de uma obra, a experiência vital e orgânica que conecta as sensações e memórias e a perspectiva de uma espectatorialidade também movida por identificações viscerais. Deste modo, não perde de vista questões subjetivas e engajamentos pessoais, considerando-os também mobilizadores do campo cinematográfico, o que permite que se volte a pensar a relação entre autoria e obra a partir de novos paradigmas, lançando outros olhares sobre um possível cinema de mulheres. 
COSTA, Petra; ZISKIND, Carolina. Elena. s.d. Roteiro ilustrado. Disponível em: $<$ http://elenafilme.com/roteiro-ilustrado>. Acesso em: 07 jan. 2014.

ELENA. Direção: Petra Costa. Produção: Bernardo Bath; Julia Bock; Petra Costa; Sara Dosa; Fernando Meirelles; Caroline Onikute; Moara Passoni; Tiago Pavan; Tim Robbins; Daniela Santos. Brasil: Busca Vida Filmes, 2012. 80 min. Son., Color., $35 \mathrm{~mm}$.

MARKS, Laura U. The skin of the film: intercultural cinema, embodiment and the senses. London: Duke University Press, 2000. Press, 2002.

Touch: sensuous theory and multisensory media. Minneapolis, USA: University of Minnesota

OLHOS de ressaca. Direção: Petra Costa. Produção: Petra Costa. Brasil: Aruac Produções, 2008. 20 min. Son., Color., $16 \mathrm{~mm}$.

SOBCHACK, Vivian. The address of the eye: a phenomenology of film experience. Nova Iorque: Princeton University Press, 1991.

Recebido em 06/02/2016. Aprovado em 18/03/2016.

Title: Petra Costa's documentary Elena, the sensorium in the embodiment of an elegy

Abstract: This article analyzes the movie Elena (2013) by Petra Costa, taking its memoir aspects from the lived body paradigm, present in the studies of Sobchack (1991) and Marks (2000, 2002). The phenomenological perspective of these authors, which understands cinema as a field where bodies result and share memory, understand the film spectatorship experience as a possibility articulated by the sensorium, cognitive capacity of interpreting sensations. Thereby, also consider the filmmakers' subjective experience as something that interferes in the film perception. We observe how the body presence, material and sensorial allows us an analysis that involves aspects of the film authorship.

Keywords: Women's Cinema. Sensorium. Lived body.

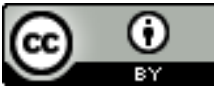

Este texto está licenciado com uma Licença Creative Commons Atribuição 4.0 Internacional. 